\title{
Should Adjuvant Radiation Therapy Be Systematically Proposed for Male Breast Cancer? A Systematic Review
}

\author{
PAULINE JARDEL ${ }^{1}$, STÉPHANE VIGNOT ${ }^{2}$, BRUNO CUTULI $^{3}$, ANNE CREISSON $^{4}$, \\ SYLVIE VASS $^{1}$, EMMANUEL BARRANGER ${ }^{5}$ and JULIETTE THARIAT ${ }^{6}$ \\ ${ }^{1}$ Department of Radiation Oncology, Chicoutimi Hospital, Saguenay, QC, Canada; \\ ${ }^{2}$ Department of Medical Oncology, Louis Pasteur Hospital, Le Coudray, France; \\ ${ }^{3}$ Department of Radiation Oncology, Courlancy Polyclinic, Reims, France; \\ Departments of ${ }^{4}$ Medical Oncology and ${ }^{5}$ Surgery, Antoine Lacassagne Anticancer Center, Nice, France; \\ ${ }^{6}$ Department of Radiation Oncology, François Baclesse Anticancer Center, Caen, France
}

\begin{abstract}
Background: Guidelines for radiotherapy in male breast cancer $(M B C)$ are lacking. Some extrapolate the results from female breast cancer trials, while others advocate systematic adjuvant irradiation. We evaluated clinical practices and outcomes with respect to radiation therapy in MBC treated with locoregional irradiation in the adjuvant setting using a systematic literature review. Material and Methods: We included studies with data about adjuvant radiotherapy published between 1984 and 2017 and including at least 40 patients. Results: We found 29 retrospective series, 10,065 men were diagnosed with breast cancer; 3-100\% (mean $=54 \%)$ received adjuvant radiotherapy. Tumor size and nodal involvement were the strongest prognostic factors. Approximatively half of all cases had nodal metastases. Radiation therapy improved locoregional control in six series, overall survival in three and distant metastasis-free survival in one. Conclusion: MBC is diagnosed at a highly advanced stage and may be linked with poorer outcomes. Adjuvant radiation therapy must, at least, be proposed to men with positive nodes. Despite the large number of cases gathered here, arguments for radiotherapy in other prognostic subgroups (especially in pNO) may exist but are not well supported.
\end{abstract}

This article is freely accessible online.

Correspondence to: Dr Juliette Thariat, MD, Ph.D., Service de Radiothérapie, Centre de Lutte Contre le Cancer François Baclesse, 3 Av. du Général Harris, 14000 Caen, France. E-mail: jthariat@ gmail.com

Key Words: Male breast cancer, radiotherapy, mastectomy, adjuvant treatment, prognostic factors, local control, review.
Breast cancer in males is infrequent, representing $1 \%$ of all breast carcinomas, and less than $1 \%$ of all male cancers (1, 2 ), even if its incidence seems to be increasing (3-7). All studies regarding male breast cancer (MBC) are retrospective and specific recommendations are sparse. The general management of non-metastatic MBC is usually based on guidelines for female breast cancer (FBC). Surgery, chemotherapy and hormonal therapy are based on classical prognostic factors. After mastectomy, which represents the majority of cases, locoregional irradiation for MBC remains controversial. Some institutions recommend systematic postmastectomy irradiation considering that $\mathrm{MBC}$ is intrinsically more aggressive than FBC and that the ratio of tumor size to gland could lead to minimal surgical margins; others suggest that the natural history of MBC resembles that of postmenopausal female breast cancer and that the aggressiveness is biased by a more advanced stage at diagnosis $(1,2,4)$. Institutions base their recommendations for MBC based on data established for females. We evaluated clinical practices and outcomes with respect to radiation therapy in MBC treated with locoregional irradiation in the adjuvant setting using a systematic literature review.

\section{Materials and Methods}

Our systematic review of the literature was based on the Preferred Reporting Items for Systematic Reviews and meta-Analysis (PRISMA) recommendations (http://www.prisma-statement.org/). Data were selected from a search on PubMed during the period 1976 to 2017 and from references in identified articles, using the following search terms: "breast cancer", "men", "male", "radiotherapy"; articles published in English or French were included. Relevant articles were selected with the following inclusion criteria: non metastatic $\mathrm{MBC}$, an original study with more 
Table I. Studies meeting the inclusion criteria.

\begin{tabular}{|c|c|c|c|c|c|c|c|}
\hline Country & Year & $\begin{array}{l}\text { First author } \\
\quad \text { (Ref.) }\end{array}$ & $\mathrm{n}$ & Era & Follow-up & $\begin{array}{c}\text { RT/ } \\
\text { no RT }\end{array}$ & $\begin{array}{c}\text { Men/ } \\
\text { women }\end{array}$ \\
\hline Canada & 1984 & Erlichman et al. (8) & 85 & 1967-1981 (14 years) & NR & Yes & No \\
\hline USA & 1992 & Borgen et al. (9) & 104 & $1975-1990$ ( 15 years $)$ & Median 67 months (range $=6$ months -15 years) & No & No \\
\hline Spain & 1994 & Izquierdo et al. (10) & 50 & 1964-1990 (26 years) & Median 65 months (range=3-185 months) & No & No \\
\hline UK & 1994 & Lartigau et al. (11) & 65 & 1968-1988 (20 years) & Median 54 months & No & No \\
\hline France & 1995 & Cutuli et al. (12) & 382 & $1960-1986$ (26 years) & Median 74 months & Yes & No \\
\hline Austria & 1995 & Stierer et al. (13) & 169 & 1970-1991 (21 years) & Median 51 months (range $=12-192$ months) & No & No \\
\hline UK & 1997 & Willsher et al. (14) & 41 & 1974-1994 (20 years) & Median 42 months & Yes & Yes \\
\hline Turkey & 1998 & Yildirim et al. (15) & 121 & 1972-1994 (22 years) & Median 29 months (range=3-146 months) & Yes & No \\
\hline USA & 2002 & Chakravarthy et al. (16) & 44 & 1967-1995 (28 years) & Median 96 months (range=8-246 months) & Yes & No \\
\hline Canada & 2005 & McDonald et al. (21) & 159 & 1989-1998 (9 years) & Median 8.4 years (range $=4.5-14.3$ years) & No & Yes \\
\hline Turkey & 2006 & Atahan et al. (17) & 42 & $1994-2001$ ( 7 years $)$ & Median 29 months (range $=4.5-118$ months) & No & No \\
\hline France & 2008 & Tunon de lara et al. (19) & 44 & 1980-2004 (24 years) & Median 136months (range $=125-146$ months) & No & No \\
\hline China & 2010 & Zhou et al. (35) & 70 & $1968-2009$ (41 years) & Median 55 months (range $=3-391$ months) & Yes & No \\
\hline France & 2010 & Cutuli et al. (20) & 489 & $1990-2005$ (15 years) & Median 58 months & No & No \\
\hline Finland & 2010 & Liukkonen et al. (22) & 58 & $1981-2006$ (25 years) & Median 5 years (1 month -24 years) & No & No \\
\hline Sweden & 2011 & Nilsson et al. (23) & 99 & 1993-2007 (14 years) & Median 4.1years & No & Yes \\
\hline Turkey & 2012 & Arslan et al. (24) & 118 & $1986-2009$ (23 years) & Median 40.9 months & Yes & No \\
\hline Canada & 2012 & Yu et al. (25) & 75 & 1977-2006 (29 years) & Median 46 months (range $=1-225$ months) & Yes & No \\
\hline France & 2012 & Dabakuyo et al. (26) & 75 & $1982-2008$ (26 years) & Median 8 years (range $=5-9$ years $)$ & Yes & No \\
\hline Germany & 2012 & Müller et al. (27) & 40 & $1982-2007$ ( 25 years $)$ & Median 47 months & No & Yes \\
\hline USA & 2013 & Moten et al. (28) & 156 & $1988-2008$ (20 years) & NR & No & Yes \\
\hline USA & 2013 & Fogh et al. (29) & 42 & $1990-2003$ (13 years) & Median 8 years (range $=3-18$ years) & No & No \\
\hline Germany & 2013 & Eggeman et al. (30) & 664 & $1970-1989$ (19 years) & Mean 26.2 years (19-38 years) & Yes & No \\
\hline Italy & 2013 & Meattini et al. (31) & 60 & 1971-2011 (40 years) & Median 8.9 years $($ range $=0.6-20$ years $)$ & Yes & No \\
\hline USA & 2013 & Fields et al. (6) & 4276 & $1973-2008$ (35 years) & NR & Yes & Yes \\
\hline Canada & 2014 & Ruschton et al. (32) & 72 & $1981-2009$ (28 years) & Median 45 months (range $=2-204$ months) & No & Yes \\
\hline USA & 2014 & Madden et al. (34) & 1337 & 1983-2002 (19 years) & Median 7.3 years (range $=1$ month -25 years) & Yes & No \\
\hline France & 2015 & Oger et al. (33) & 95 & $2000-2010$ (10 years) & Median 45 months (range $=7-132$ months) & No & No \\
\hline
\end{tabular}

n: Number of men; NR: not reported. The two last columns indicate whether the authors compared outcomes by whether radiotherapy was given or not and between men and women.

than 40 patients receiving irradiation, inclusions beginning after 1960. full text availability and details on radiotherapy procedures (articles were excluded if radiotherapy was not specifically studied). Repeated publications were only selected once. Characteristics of MBC and treatment modalities were extracted. Impact on local tumor control and survival was estimated.

\section{Results}

Relevant articles. One hundred and seventy-one articles were identified and assessed. Twenty-nine of them met the inclusion criteria (Figure 1 and Table I), involving 10,965 men diagnosed with breast cancer $(6,8-35)$. No prospective study had been published. Average follow-up was between 7 and 314 months (median=60 months). The number of patients per study was between 40 and 664 (mean=82), except for three studies utilizing national databases (with $4,276,1,933$, and 1,337 patients, respectively) $(6,18,34)$. Patients were treated during the period 1960-2013. Mean inclusion time was 22 years (range $=7-41$ years). Males were matched with females in seven of the series. Comparisons of outcomes with or without post-mastectomy radiotherapy were available in 14 of the articles reviewed.

$M B C$ characteristics. Clinical and pathological characteristics of patients with MBC as described in selected publications are presented in Table II. The median age was 63 years (range of the median $=55$ to 68 years). Pre-existing comorbidities were frequent in this population: $42 \%$ of the patients had one or more chronic disease, increasing with age $(20,21,30)$. Tunon de Lara et al. showed that $57 \%$ (20/35 patients for whom the body mass index could be evaluated) were overweight (19).

The most tumor common type was invasive ductal carcinoma $(80-95 \%)$, followed by ductal carcinoma in situ (5-10\%) (36). Estrogen receptor (ER) was expressed in $88 \%$ of cases. The expression of human epidermal growth factor receptor 2 (HER2) was reported in the most recent studies and estimated as positive in $15 \%$ of cases. Studies were not 


\section{Records identified through medline database searching \\ (((male[Title]) OR men[Title]) AND radiotherapy[Title/Abstract]) AND breast cancer $\mathrm{n}=\mathbf{1 3 1}$}

\section{Additional records identified}

$\mathrm{n}=\mathbf{3 9}$

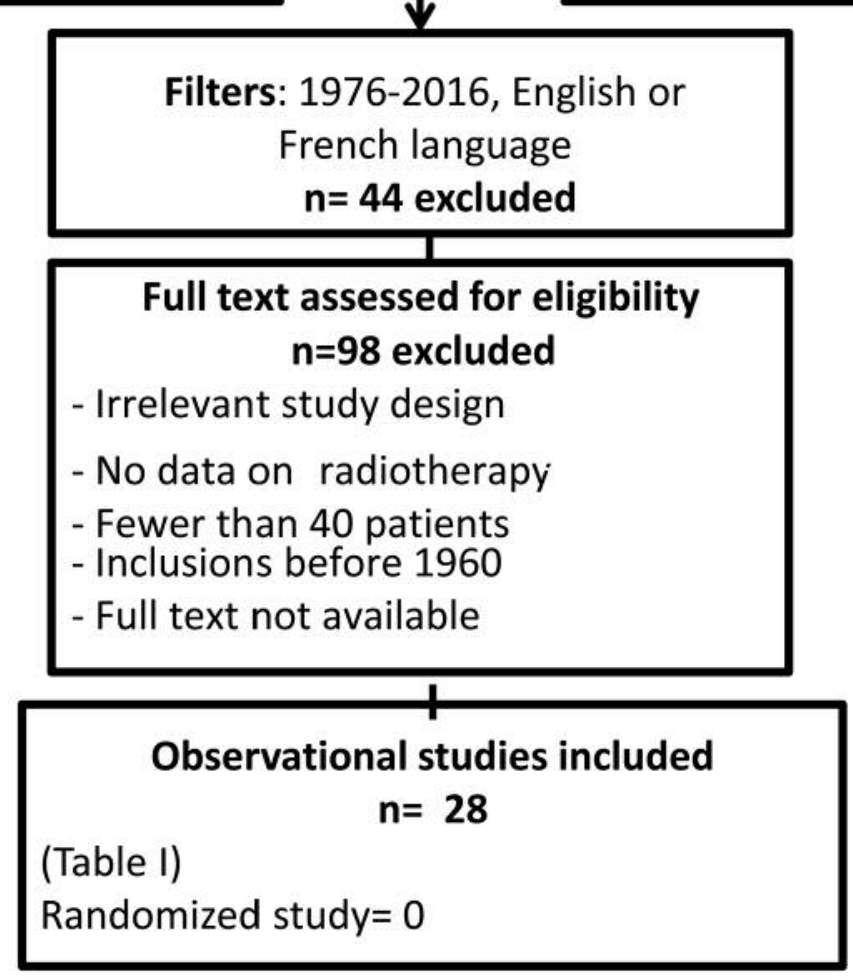

Figure 1. Study design.

unequivocal concerning the histological grade distribution in males in comparison with females; the largest comparative study by Fields et al. found a similar distribution of grades. In their study, $23 \%$ of tumors were pT4 and $50 \%$ presented nodal involvement. A large tumor size was associated with poorer outcomes (6). Lartigau et al. reported a significant difference in 10-year disease-specific survival between those with $\mathrm{T} 4$ and those with $\mathrm{T} 1$ tumors (32\% versus $87 \%$, $p=0.001$ ) (11); Cutuli et al. reported 10-year disease-specific survival rates for those with T0-T1, T2 and T3-T4 of $81 \%$, $80 \%$ and $69 \%$, respectively (20). Lymph node involvement was a strong prognostic factor in most MBC studies (15, $31,34,36,37)$. The 10 -year survival was $28 \%$ when lymph nodes were not involved versus $58 \%$ when involved (12). Such data were reported before the systematic use of sentinel node biopsy in females. Omission of axillary dissection led to increased regional nodal relapses rates in $\operatorname{MBC}(12,13)$.
In our analysis, eight studies were before 1990 (8-13, 16, $30)$, eight after $(17,18,20-24,29,33)$, and the remaining study covered longer periods. The frequency of T4 stage cases tended to decrease with time: $26 \%$ (range $=11-71 \%$ ) versus $13 \%$ (range $=10-20 \%$ ) on average between these two time periods. The percentage of involved nodes was $48 \%$ (range $=35-57 \%$ ) in the oldest series and $43 \%$ (range $=31$ $62 \%$ ) in the newest.

Surgery. Surgical approaches were similar to those used in FBC. Radical mastectomy was the main surgical procedure until the 1970s. The studies showed a progressive decrease in the rate of radical mastectomy over the past several decades, being replaced by modified radical mastectomy, with equivalent general locoregional relapse rates $(12,34,35)$. Rates of patients who underwent breast partial surgery varied between 5 and $25 \%$ (mean=7\%). Partial mastectomies were 
more likely proposed in a palliative context in older men with advanced disease, even though they could also have been performed in those with limited disease for better cosmetic, functional and psychological tolerance (29). Surgical procedures for axillary nodes (dissection, sentinel node biopsy or both) were performed in $45 \%$ to $100 \%$ in the whole series of patients $($ mean $=91 \%)$. However, strictly speaking modified radical mastectomy includes an axillary dissection.

Adjuvant systemic treatments. Adjuvant hormonal treatment and chemotherapy has increased over the past decades $(24,26$, $36,38)$. The rate of patients who received chemotherapy varied between 3 and $85 \%$ (mean=26\%) and hormonal therapy between 7 and $92 \%($ mean=45\%). In a French series including patients between 1990 and 2005, hormonal treatment was delivered in $72 \%$ of the cases (tamoxifen represented $85 \%$ and aromatase inhibitors, $12 \%$ ) and increased over time (57\%, $74 \%$ and $82 \%$ in 1988-1995, 1996-2000 and 2001-2005, respectively, $p<0.0001$ ); adjuvant chemotherapy was delivered in $34 \%$ of the cases with an anthracycline-based regimen in $73 \%$ (25\% in $1988-1995$ and $37 \%$ in $1996-2005, p=0.029$ ) (20). In a matched series in the United Kingdom (period 19632006; males and females were matched according to age, tumor size, nodal status, margins, and treatments), chemotherapy was given in $16 \%$ of the males and $45.5 \%$ of the females, although nodal invasion accounted for $51 \%$ of MBC cases and $56 \%$ of FBC cases (39).

Adjuvant radiotherapy. The utilization of postoperative radiotherapy in males varied between $3 \%$ and $100 \%$ (mean $=64 \%$ ). The choice of target volumes (chest wall, nodal areas, and boost) was not clearly stated in most studies. In a cohort of 75 patients reported by Yu et al., radiotherapy was indicated for the chest wall after mastectomy (with or without supraclavicular/axillary/internal mammary nodes) in high-risk patients with close/positive margins, positive nodes and pT3 (25). MacDonald et al. showed that radiotherapy was almost six times more likely given to males than females (even with the exclusion of T4 cases). Withholding radiotherapy was either advocated in females with good prognostic factors or males with poor performance status (21). Indications and techniques of radiation therapy were not systematically reported and varied depending on authors/countries and periods (with the use of cobalt and orthovoltage in earlier periods) $(6,20,35)$. Müller et al. mentioned an electron beam rotational technique for the chest wall (27). Tangential fields were adjusted seeking to include more nodal tissue (first axillary area or internal mammary nodes) $(27,40)$. Total dose was around $50 \mathrm{~Gy}$ in 25 fractions in most studies. Lower total doses or hypofractionation in subgroups of elderly patients were not identified. Younger patients were more likely to receive adjuvant radiotherapy (30). Some authors used boost to the chest wall, for incomplete resection or tumor classified
Table II. Clinical and pathological characteristics of male breast cancer.

\begin{tabular}{lcc}
\hline Characteristic & Mean & Range \\
\hline Number of patients & 9,032 & $41-4276$ \\
Age at diagnosis, years & 63 & $24-97$ \\
Diagnosis before 50 years old & $13 \%$ & $10.5-16 \%$ \\
Delay before treatment & 6 Months & $3-13$ Months \\
Most frequent tumor location: Retroareolar & $76 \%$ & $66-86 \%$ \\
Multi-centric/focal & - & (Two reports: \\
& & 1 and 9\%) \\
Inflammatory breast & $4 \%$ & $0-8 \%$ \\
Tumor size & $2.25 \mathrm{~cm}$ & $1.8-3 \mathrm{~cm}$ \\
Invasive ductal carcinoma & $90 \%$ & $80-100 \%$ \\
Grade 3 & $28 \%$ & $12-70 \%$ \\
ER+ & $88 \%$ & $77-100 \%$ \\
pT1 & $37 \%$ & $3-77 \%$ \\
pT2 & $34 \%$ & $11-56 \%$ \\
pT3 & $12 \%$ & $2-42 \%$ \\
pT4 & $23 \%$ & $10-71 \%$ \\
pN+ & $50 \%$ & $31-74 \%$ \\
Including pN2, pN3 & $18 \%$ & $2-43 \%$ \\
\hline
\end{tabular}

ER+: Estrogen receptor expression. Mean numbers were calculated from all available series. Conclusions about human epidermal growth factor receptor 2 (HER2) cannot be drawn since its evaluation was generally not performed before 2005; for instance, HER/2neu was overexpressed in 7\% of MBC in Oger et al. (24), 23\% in Arslan et al. (33).

as T4 $(11,13,27)$. After partial mastectomy, radiation therapy was not systematically given. In a large American database (1983-2009), of the 718 males that underwent lumpectomy, $35.4 \%$ received adjuvant radiation therapy (41). In ScottConner et al.'s study matching 3627 males and females during the period 1985-1994 (using United States national database), the minority of males who underwent lumpectomy were less likely to receive adjuvant radiation therapy than females (42).

Impact of radiotherapy on local control and overall survival. The influence of radiotherapy on locoregional control is reported in Table III. Eggeman et al. found a statistical benefit in overall survival rates between patients with stage III disease treated by adjuvant radiotherapy compared to those without (10-year overall survival $=26.4 \%$ vs. $11.9 \%$ ), whereas it was not significant in the entire group (30). On the other hand, using a national database, Madden et al. showed a significant survival benefit for post mastectomy radiotherapy in stage $I$ with a positive trend for the other stages, without improved specific survival (1,337 patients). Adjuvant radiotherapy for tumors larger than $5 \mathrm{~cm}$ tended to improve overall survival and relative survival in this study (34). Patients who received adjuvant radiotherapy with N2 and $\mathrm{N} 3$ disease had a trend towards an increase in overall and specific survival (in this cohort, $25 \%$ of patients underwent 
Table III. Influence of radiotherapy on locoregional control of male breast cancer.

\begin{tabular}{|c|c|c|c|c|c|c|c|c|c|}
\hline \multirow[b]{2}{*}{ Country } & \multirow[b]{2}{*}{ Author, year (Ref) } & \multirow[b]{2}{*}{ Era } & \multirow[b]{2}{*}{$\mathrm{n}$} & \multirow[b]{2}{*}{$\begin{array}{c}\text { Partial } \\
\text { mastectomy }\end{array}$} & \multirow[b]{2}{*}{ EBRT } & \multicolumn{2}{|c|}{ Locoregional failure* } & \multirow[b]{2}{*}{$\begin{array}{l}\text { Distant } \\
\text { failure }\end{array}$} & \multirow[b]{2}{*}{ OS (5-year) } \\
\hline & & & & & & No EBRT & EBRT & & \\
\hline Canada & Erlichman et al., 1984 (8) & $1967-1981$ & 85 & $7 \%$ & $67 \%$ & $\begin{array}{c}\text { LR (5-year): } \\
31 \%\end{array}$ & $\begin{array}{l}\text { LR (5-year) } \\
\text { 26\% }\end{array}$ & $\sim 52 \% \ddagger$ & $\begin{array}{c}\sim 64 \% \text { (No EBRT) } \\
\sim 52 \% \ddagger(\text { EBRT })\end{array}$ \\
\hline France & Cutuli et al., 1995 (12) & $1960-1986$ & 373 & $13 \%$ & $51 \%$ & $\begin{array}{c}\text { LR: } 11.5 \% \\
\text { RR:5.5\% }\end{array}$ & $\begin{array}{l}\text { LR: } 4.7 \% \\
\text { RR:2.1\% }\end{array}$ & $\sim 40 \% \ddagger$ & $\sim 65 \% \ddagger$ \\
\hline UK & Willsher et al., 1997 (14) & 1974-1994 & 41 & $7 \%$ & $25 \%$ & $\begin{array}{l}\text { LR: } 27 \% \\
\text { RR: } 47 \% * *\end{array}$ & $\begin{array}{l}\text { LR: } 10 \% \\
\text { RR:20\% }\end{array}$ & $34 \%$ & $\sim 55 \%$ \\
\hline USA & $\begin{array}{c}\text { Chakra-varthy et al., } \\
2002 \text { (16) }\end{array}$ & 1967-1995 & 44 & $4 \%$ & $30 \%$ & $\begin{array}{l}\text { 1 Patient } \\
\text { (pN0) }\end{array}$ & $\begin{array}{l}2 \text { Patients } \\
\text { (pN2) }\end{array}$ & $14 \%$ & $75 \%$ \\
\hline Canada & Yu et al., 2012 (25) & $1977-2006$ & 75 & $4 \%$ & $61 \%$ & $24 \%$ & $4 \%$ & $\begin{array}{c}37 \% \text { (EBRT) vs. } \\
7 \% \text { (no EBRT) }\end{array}$ & $74 \%$ \\
\hline Italy & Meattini et al., 2013 (31) & $1971-2011$ & 60 & $3 \%$ & $43 \%$ & LR: $12 \%$ & $\begin{array}{l}\text { LR: } 4 \% \\
\text { (significant) }\end{array}$ & $27 \%$ & (8.9 years) $53 \%$ \\
\hline
\end{tabular}

LR: Local recurrence (chest wall), RR: regional recurrence (axillary or supraclavicular nodes), EBRT: external-beam radiation therapy, OS: overall survival, n: number of patients who underwent surgery. *Total recurrences; **more than $50 \%$ of the patients did not undergo axillary dissection; ‡approximately, of the entire cohort or from graphs.

Table IV. Comparison of overall survival in male breast cancer (MBC) and female breast cancer (FBC).

\begin{tabular}{|c|c|c|c|c|c|c|}
\hline \multirow[b]{2}{*}{ Author, year of publication (Ref) } & \multicolumn{2}{|c|}{$\mathrm{n}$} & \multirow[b]{2}{*}{ Stratification } & \multicolumn{2}{|c|}{ Overall survival } & \multirow[b]{2}{*}{$p$-Value } \\
\hline & $\mathrm{MBC}$ & FBC & & $\mathrm{MBC}$ & FBC & \\
\hline Mc Donald et al. 2005 (21) & 60 & 4181 & Age, nodal status & $\begin{array}{c}\text { 5-Year: } 75 \% \\
\text { 10-Year: } 53 \%\end{array}$ & $\begin{array}{c}\text { 5-Year: } 82 \% \\
10 \text {-Year: } 65 \%\end{array}$ & 0.11 \\
\hline Willsher et al. 1997 (14) & 41 & 123 & Age, grade and stage, time & 5-Year: $55 \%$ & 5 -Year: $65 \%$ & 0.27 \\
\hline Nilsson et al. 2011 (23) & 99 & 396 & $\begin{array}{l}\text { No difference in stage } \\
\text { between MBC and FBC }\end{array}$ & 5-Year: $41 \%$ & 5-Year: $55 \%$ & 0.001 \\
\hline Müller et al. 2012 (27) & 40 & - & $\begin{array}{l}\text { Virtual matching } \\
\text { (Adjuvant!Online }{ }^{\circledR} \text { ) }\end{array}$ & $\begin{array}{c}\text { 5-Year: } 66 \% \\
\text { 10-Year: } 43 \%\end{array}$ & $\begin{array}{l}\text { 10-Year: With } \\
\text { comparable } \\
\text { treatment: } 59 \% \\
\text { With optimal } \\
\text { treatment: } 68 \%\end{array}$ & $<0.001$ \\
\hline Ruschton et al. 2014 (32) & 72 & 72 & Age, time and stage & 5-Year: $80 \%$ & 5-Year: $80 \%$ & $\begin{array}{c}\text { Not reported, } \\
\text { (hazard ratio }=1.345 \text { ) }\end{array}$ \\
\hline Yu et al. 2015 (39) & 75 & 1313 & $\begin{array}{c}\text { Age, } \mathrm{pT}, \mathrm{SBR}, \text { margins, } \\
\mathrm{pN} \text {, treatment }\end{array}$ & 5-Year: 70\% & 5-Year: $\sim 80 \%$ & 0.009 \\
\hline
\end{tabular}

SBR: Scarff-Bloom-Richardson grading.

postsurgical irradiation -without details concerning the volumes-although more than half presented a nodal invasion). A significantly worse prognosis was reported by McDonald et al. in males treated with radiotherapy compared to those without (21). Close margins were detailed in one study: Yu et al. demonstrated a trend in favor of radiotherapy for patients with close or unknown margins (25).

The study from the Surveillance, Epidemiology and End Results Program (SEER) database published by Abrams et al. in 2016, included 1933 patients in the entire cohort and 5-year overall survival was not significantly different between those receiving adjuvant radiotherapy and those not ( $78 \%$ vs. $77 \%$, respectively, $p=0.371$ ). But in 315 cases in the same cohort, matched by ER status, T-stage, N-stage, race, histological grade and age, the use of adjuvant radiotherapy provided a benefit in 5-year overall survival ( $83 \%$ versus $54 \%, p<0.001$ ). In patients with positive lymph nodes, for the entire unmatched cohort, the benefit of 
radiotherapy achieved significance: 5-year overall survival was $79 \%$ versus $72 \%, p=0.05$ in the group with one to three positive nodes, and $73 \%$ versus $53 \%, p<0.001$ in the group with four and more positive nodes (18).

Studies comparing overall survival in MBC and FBC are additionally presented in Table IV.

\section{Discussion}

We achieved the gathering of data on 10.965 males over four decades, and this constitutes the largest review of the role of adjuvant irradiation for MBC. After mastectomy, radiotherapy improved local control in males with breast cancer according to available retrospective data reported in Table III, similarly as demonstrated prospectively for FBC (43). Radiotherapy also improved the overall survival, all the more so in men with positive lymph nodes. Our analysis reveals an inconstant use of radiotherapy after $\mathrm{MBC}$ and this finding raises some questions.

Important biases must be considered. The analysis is based on retrospective, often small, studies. The data were published over a long period which could lead to important variations in diagnosis and treatment modalities. For example, Cutuli et al. reported 5- and 10-year diseasespecific survival rates of $74 \%$ and $51 \%$ in a first study (1960-1986) and $89 \%$ and $72 \%$ in a more recent survey (1990-2005) $(12,20)$. This improvement could be linked to better treatments or to earlier diagnosis. These studies report a reversal in the pattern of distribution between $\mathrm{T} 1$ and $\mathrm{T} 2$ in time: $20 \%$ of $\mathrm{T} 1$ and $41 \%$ of $\mathrm{T} 2$ in the first period compared to $47 \%$ of $\mathrm{T} 1$ and $20 \%$ of $\mathrm{T} 2$ in the second publication; T3-T4 stages accounted for about 30\%. As described, the ratio of involved nodes did not change $(53 \%$ and $56 \%$ ), with approximately $20 \%$ of pN2 or more. But, even if $\mathrm{T} 1$ stages increased compared to $\mathrm{T} 2$ tumors, the rate of locally advanced MBC remained stable throughout the period. Improvement of the prognosis could therefore hardly be associated only with earlier diagnosis with modification of the stage distribution. Moreover, in the same period, the use of systemic treatments increased. As for radiation therapy, it is difficult to conclude that its use increased globally during this time because of the study's heterogeneity. However, studies from the large SEER American database showed a significant increase in the use of post-mastectomy radiotherapy over time $(24.3 \%$ in 1973 1987 to $36.8 \%$ in $1998-2008$, Fields et al. $(6,18)$.

MBC is often considered to be similar to post-menopausal FBC and treatment could, therefore, be based on the same recommendations. This assumption is questionable since important differences are emphasized in our analysis. MBC cases are mainly ductal since male breast lobules are not fully developed. MBC is rare before the age of 50 years and hormonal receptor positivity is more frequently reported.
Nilsson et al. analyzed microarrays of $197 \mathrm{MBCs}$ and found positivity for ER of $93 \%$, PR of $77 \%$, HER/2neu of $11 \%$, with grade III (Nottingham) of $41 \%$, luminal A of $81 \%$, luminal B $11 \%$, and rare basal-like phenotypes. This underlines a major gender difference since luminal A profile accounts for 44-66\% of FBC, luminal B 6-19\%, basal-like 10-17\% and HER2-like 8-10\% (44). Differences in genomic and molecular profiles between $\mathrm{MBC}$ and $\mathrm{FBC}$ suggest that these are different diseases $(2,23,36,45)$. Other significant differences in the immunostaining of MBC compared with FBC were also reported (46). A study published in 2016 showed, for instance, that a smaller percentage of MBCs compared to FBCs had mutation of phosphatidylinositol-4,5bisphosphate 3-kinase catalytic subunit alpha (PIK3CA), this being the second most frequently mutated gene in FBC and the object of intense research for targeted therapies (47).

When considering the lack of screening with mammography, the predominance of $\mathrm{T} 1$ and $\mathrm{T} 2$ stages in most studies could be explained by the small breast volume in men, in which lesions are easily palpable. Moreover, delays in care are improving, perhaps due to increased public awareness $(23,48)$. However, nodal invasion remains at approximately $50 \%$ of $\mathrm{MBC}$, with $20 \%$ or more of $\mathrm{pN} 2$, supporting the hypothesis of a higher risk of nodal invasion in $\mathrm{MBC}$, even in those with small tumor size.

Comparisons between cohorts with matched MBC and FBC patients should then be considered with caution. Overall survival was often lower in MBC than in FBC even if not always significantly different. The comparison in outcomes according to gender is difficult as men were more likely undertreated, with less applied chemotherapy and less radiotherapy $(25,49)$. Men are additionally at higher risk of other cancer types and mortality causes (50). Older age at diagnosis results in higher comorbidities that could contribute to less access to therapies.

Considering adjuvant radiotherapy, in the absence of definitive data, it appears reasonable to support, at least, the use of the same recommendations as those available for FBC. After partial mastectomy, adjuvant radiotherapy appears mandatory. After radical mastectomy, chest wall irradiation is to be considered for men with involved nodes. In pN0. similar risk factors as in women (size, high grade, negativity for hormonal receptors, expression of HER2neu, lymphovascular invasion, dermal invasion) should be evaluated, but evidence is lacking. It is not possible to define precisely the target volumes such as the internal mammary nodes, a question that is still under debate for FBC. Data are also lacking in case of multifocality/multicentricity, and for inflammatory MBC. In the case of positive margins, one study showed a trend for a benefit with radiotherapy but we consider that positive margins should lead to repeat surgery as first intention and irradiation to the chest wall, possibly with a boost for residual disease if not resectable (25). 
Some authors are in favor of a more aggressive treatment: Gennari et al., for example, proposed radiation therapy for tumors larger than $1 \mathrm{~cm}$ considering the small volume of the breast gland in males, especially since the male anatomy might facilitate early chest wall spread (51).

After MBC surgery, it is important to identify the situations where radiotherapy can be omitted in order to avoid exposure to unnecessary toxicity for the patient and unjustified costs. On the other hand, it remains important to emphasize the importance of adjuvant radiotherapy when indicated as our analysis reports its underuse in some cases, especially after partial mastectomy. Toxicity and impact on quality of life, which are potentially associated with adjuvant radiotherapy, could be considered as an issue for these patients who appear to be older and with more comorbidities than FBC patients. We consider that adjuvant irradiation can be proposed in safe conditions for these patients and that future evolution in radiotherapy will allow safer treatment modalities, even if new approaches have not been specifically evaluated in MBC. Hypofractionated regimens have not included men (neither in the English START trial nor the Canadian trial $(52,53)$. However modification of radiotherapy regimens due to age should be discussed in order to favor access to treatment when indicated. With dedicated computed tomographic scan planning, it is now possible to control the dose delivered to cardiac and pulmonary structures, especially in left-sided breast cancer, an important issue since male patients tend to have a higher incidence of coronary artery disease. The technique including internal mammary nodes in the tangential field appears to be of particular interest in this population $(40,54)$.

Despite the large number of cases collected in this review, it should be noted that arguments for radiotherapy in other prognostic subgroups than those with positive nodes, in which it is well supported, are not proven, but were also not excluded. It is, therefore, important to report real-life results from former series in order to assess the security of current practice. Large prospective cohort studies should be instigated for MBC. Such studies are difficult to conduct considering the epidemiology of MBC and the minor economic issues. At the same time, collaborative approaches should better characterize MBC with clinical and biological data, as proposed in the project "Male Breat Cancer: Understanding the Biology for Improved Care" initiated in 2010 and sponsored by the European Organisation for Research and Treatment of Cancer (NCT01101425).

\section{Conflicts of Interest}

The Authors have no actual or potential conflicts of interest including any financial, personal or other relationships with people or organizations within three years of beginning the submitted work that could inappropriately influence, or be perceived to influence, their work.

\section{References}

1 Gómez-Raposo C, Zambrana Tévar F, Sereno Moyano M, López Gómez M and Casado E: Male breast cancer. Cancer Treat Rev 36(6): 451-457, 2010.

2 Fentiman IS, Fourquet A and Hortobagyi GN: Male breast cancer. Lancet Lond Engl 367(9510): 595-604, 2006.

3 Giordano SH, Cohen DS, Buzdar AU, Perkins G and Hortobagyi GN: Breast carcinoma in men: a population-based study. Cancer 101(1): 51-57, 2004.

4 Anderson WF, Jatoi I, Tse J and Rosenberg PS: Male Breast Cancer: A Population-Based Comparison With Female Breast Cancer. J Clin Oncol 8(2): 232-239, 2010.

5 Hodgson NCF, Button JH, Franceschi D, Moffat FL and Livingstone AS: Male breast cancer: is the incidence increasing? Ann Surg Oncol 11(8): 751-755, 2004.

6 Fields EC, DeWitt P, Fisher CM and Rabinovitch R: Management of male breast cancer in the United States: a surveillance, epidemiology and end results analysis. Int J Radiat Oncol Biol Phys 87(4): 747-752, 2013.

7 White J, Kearins O, Dodwell D, Horgan K, Hanby AM and Speirs V: Male breast carcinoma: increased awareness needed. Breast Cancer Res 13(5): 219, 2011.

8 Erlichman C, Murphy KC and Elhakim T: Male breast cancer: a 13-year review of 89 patients. J Clin Oncol 2(8): 903-909, 1984.

9 Borgen PI, Wong GY, Vlamis V, Potter C, Hoffmann B, Kinne DW, Osborne MP and McKinnon WM: Current management of male breast cancer. A review of 104 cases. Ann Surg 215(5): 451-457; discussion 457-459, 1992.

10 Izquierdo MA, Alonso C, De Andres L and Ojeda B: Male breast cancer. Report of a series of 50 cases. Acta Oncol Stockh 33(7): 767-771, 1994

11 Lartigau E, el-Jabbour JN and Dubray B and Dische S: Male breast carcinoma: a single centre report of clinical parameters. Clin Oncol 6(3): 162-166, 1994.

12 Cutuli B, Lacroze M, Dilhuydy JM, Velten M, De Lafontan B, Marchal C, Resbeut M, Graic Y, Campana F and Moncho-Bernier V: Male breast cancer: results of the treatments and prognostic factors in 397 cases. Eur J Cancer 31A(12): 1960-1964, 1995.

13 Stierer M, Rosen H, Weitensfelder W, Hausmaninger H, Teleky B, Jakesz R, Fruhwirth H, Dünser M, Beller S and Haid A: Male breast cancer: Austrian experience. World J Surg 19(5): 687-692; discussion 692-693, 1995.

14 Willsher PC, Leach IH, Ellis IO, Bourke JB, Blamey RW and Robertson JF: A comparison outcome of male breast cancer with female breast cancer. Am J Surg 173(3): 185-188, 1997.

15 Yildirim E and Berberoğlu U: Male breast cancer: a 22-year experience. Eur J Surg Oncol J Eur Soc Surg Oncol 24(6): 548$552,1998$.

16 Chakravarthy A and Kim CR: Post-mastectomy radiation in male breast cancer. Radiother Oncol J Eur Soc Ther Radiol Oncol 65(2): 99-103, 2002.

17 Atahan L, Yildiz F, Selek U, Sari S and Gurkaynak M: Postoperative radiotherapy in the treatment of male breast carcinoma: a single institute experience. J Natl Med Assoc 98(4): 559-563, 2006.

18 Abrams MJ, Koffer PP, Wazer DE and Hepel JT: Postmastectomy radiation therapy is associated with improved survival in node-positive male breast cancer: a population analysis. Int J Radiat Oncol 98(2): 384-391, 2017. 
19 Tunon de Lara C, Goudy G, Macgrogan G, Durand M, Dilhuydy J-M, Avril A, Stoeckle E, Bussieres, J-E, Debed M, de Mascarel I and Mauriac L: Male breast cancer: a review of 52 cases collected at the Institute Bergonié (Bordeaux, France) from 1980 to 2004. Gynécologie Obstétrique Fertil 36(4): 386394, 2008.

20 Cutuli B, Le-Nir CC-S, Serin D, Kirova Y, Gaci Z, Lemanski C, De Lafontan B,Zoubir M, Maingon P, Mignotte H,Tunon de Lara C,Edeline J, Penault-Llorca F, Romestaing P,Delva C,Comet B and Belkacemi Y: Male breast cancer. Evolution of treatment and prognostic factors. Analysis of 489 cases. Crit Rev Oncol Hematol 73(3): 246-254, 2010.

21 Macdonald G, Paltiel C, Olivotto IA and Tyldesley S: A comparative analysis of radiotherapy use and patient outcome in males and females with breast cancer. Ann Oncol Off J Eur Soc Med Oncol ESMO 16(9): 1442-1448, 2005.

22 Liukkonen S, Saarto T, Mäenpää $H$ and Sjöström-Mattson J: Male breast cancer: a survey at the Helsinki University Central Hospital during 1981-2006. Acta Oncol Stockh Swed 49(3): 322-327, 2010.

23 Nilsson C, Holmqvist M, Bergkvist L, Hedenfalk I, Lambe M and Fjällskog M-L: Similarities and differences in the characteristics and primary treatment of breast cancer in men and women - a population based study (Sweden). Acta Oncol 50(7): 1083-1088, 2011.

24 Arslan UY, Oksüzoğlu B, Ozdemir N, Aksoy S, Alkış N, Gök A, Kaplan M, Gümüs M, Berk, V, Uncu D, Baykara M, Çolak D, Üyetürk Ü, Türker I and Isikdogan A: Outcome of nonmetastatic male breast cancer: 118 patients. Med Oncol 29(2): 554-560, 2012.

25 Yu E, Suzuki H, Younus J, Elfiki T, Stitt L, Yau G, Vujovic O, Perera F, Lock M and Tai P: The impact of post-mastectomy radiation therapy on male breast cancer patients - a case series. Int J Radiat Oncol Biol Phys 82(2): 696-700, 2012.

26 Dabakuyo TS, Dialla O, Gentil J, Poillot M-L, Roignot P, Cuisenier $\mathbf{J}$ and Arveux P: Breast cancer in men in Cote d'Or (France): epidemiological characteristics, treatments and prognostic factors. Eur J Cancer Care 21(6): 809-816, 2012.

27 Müller A-C, Gani C, Rehm HME, Eckert F, Bamberg M, Hehr $\mathrm{T}$ and Weinmann M: Are there biologic differences between male and female breast cancer explaining inferior outcome of men despite equal stage and treatment? Strahlenther Onkol Organ Dtsch Röntgenges Al 188(9): 782-787, 2012.

28 Moten A, Obirieze A and Wilson LL: Characterizing lobular carcinoma of the male breast using the SEER database. J Surg Res 185(2): e 71-76, 2013.

29 Fogh S, Kachnic LA, Goldberg SI, Taghian AG, Powell SN and Hirsch AE: Localized therapy for male breast cancer: functional advantages with comparable outcomes using breast conservation. Clin Breast Cancer 13(5): 344-349, 2013.

30 Eggemann H, Ignatov A, Stabenow R, von Minckwitz G, Röhl FW, Hass P and Costa SD: Male breast cancer: 20-year survival data for post-mastectomy radiotherapy. Breast Care 8(4): 270275, 2013.

31 Meattini I, Livi L, Franceschini D, Saieva C, Scotti V, Casella D, Criscenti V, Zanna I, Meacci F, Gerlain E, Agresti B, Mangoni M, Paiar F, Simontacchi G, Greto D, Nori J, Bianchi $\mathrm{S}$, Cataliotti L and Biti G: Treatment of invasive male breast cancer: a 40-year single-institution experience. Radiol Med 118(3): 476-486, 2013
32 Rushton M, Kwong A, Visram H, Graham N, Petrcich W and Dent S: Treatment outcomes for male breast cancer: a singlecentre retrospective case-control study. Curr Oncol 21(3): e400407, 2014.

33 Oger A-S, Boukerrou M, Cutuli B, Campion L, Rousseau E, Bussières E, Raro $\mathrm{P}$ and Classe JM: Male breast cancer: prognostic factors, diagnosis and treatment: a multi-institutional survey of 95 cases. Gynécologie Obstétrique Fertil 43(4): 290296, 2015.

34 Madden NA, Macdonald OK, Call JA, Schomas DA, Lee CM and Patel S: Radiotherapy and male breast cancer: a populationbased registry analysis. Am J Clin Oncol 39(5): 458-462, 2016.

35 Zhou F-F, Xia L-P, Guo G-F, Wang X, Yuan Z-Y, Zhang B and Wang F: Changes in therapeutic strategies in Chinese male patients with breast cancer: 40 years of experience in a single institute. Breast 19(6): 450-455, 2010.

36 Korde LA, Zujewski JA, Kamin L, Giordano S, Domchek S, Anderson WF, Bartlett JM, Gelmon K, Nahleh Z, Bergh J, Cutuli B, Pruneri G, McCaskill-Stevens W, Gralow J, Hortobagyi G and Cardoso F: Multidisciplinary meeting on male breast cancer: summary and research recommendations. J Clin Oncol 28(12): 2114-2122, 2010.

37 Kiluk JV, Lee MC, Park CK, Meade T, Minton S, Harris E, Kim $\mathrm{J}$ and Laronga $\mathrm{C}$ : Male breast cancer: management and followup recommendations. Breast J 17(5): 503-509, 2011.

38 Ottini L: Male breast cancer: a rare disease that might uncover underlying pathways of breast cancer. Nat Rev Cancer 14(10): 643-644, 2014.

39 Yu E, Stitt L, Vujovic O, Joseph K, Assouline A, Younus J, Perera $\mathrm{F}$ and Tai P: Male breast cancer prognostic factors versus female counterparts with propensity scores and matched-pair analysis. Cureus 7(10): e355, 2015.

40 Bratman SV, Kapp DS and Horst KC: Evolving trends in the initial locoregional management of male breast cancer. Breast 21(3): 296-302, 2012.

41 Cloyd JM, Hernandez-Boussard T and Wapnir IL: Outcomes of partial mastectomy in male breast cancer patients: analysis of SEER, 1983-2009. Ann Surg Oncol 20(5): 1545-1550, 2013.

42 Scott-Conner CEH, Jochimsen PR, Menck HR and Winchester DJ: An analysis of male and female breast cancer treatment and survival among demographically identical pairs of patients. Surgery 126(4): 775-781, 1999.

43 EBCTCG (Early Breast Cancer Trialists' Collaborative Group), McGale P, Taylor C, Correa C, Cutter D, Duane F, Ewertz M, Gray R, Mannu G, Peto R, Whelan T, Wang Y, Wang Z and Darby $S$ : Effect of radiotherapy after mastectomy and axillary surgery on 10-year recurrence and 20-year breast cancer mortality: meta-analysis of individual patient data for 8135 women in 22 randomised trials. Lancet 383(9935): 2127-2135, 2014.

44 Nilsson C, Johansson I, Ahlin C, Thorstenson S, Amini R-M, Holmqvist M, Bergkvist L, Hedenfalk I and Fjällskog ML: Molecular subtyping of male breast cancer using alternative definitions and its prognostic impact. Acta Oncol 52(1): 102109, 2013.

45 André S, Pinto AE, Laranjeira C, Quaresma M and Soares J: Male and female breast cancer--differences in DNA ploidy, $\mathrm{p} 21$ and 553 expression reinforce the possibility of distinct pathways of oncogenesis. Pathobiol J Immunopathol Mol Cell Biol 74(6): 323-327, 2007 
46 Fentiman IS: Male breast cancer is not congruent with the female disease. Crit Rev Oncol Hematol 101: 119-124, 2016.

47 Piscuoglio S, Ng CKY, Murray MP, Guerini-Rocco E, Martelotto LG, Geyer FC, Bidard FC, Berman S, Fusco N, Sakr RA, Eberle CA, De Mattos-Arruda L, Macedo GS, Akram M, Baslan T, Hicks JB, King TA, Brogi E, Norton L, Weigelt B, Hudis CA and Reis-Filho JS: The genomic landscape of male breast cancers. Clin Cancer Res 22(16): 4045-4056, 2016.

48 Cutuli B: Strategies in treating male breast cancer. Expert Opin Pharmacother 8(2): 193-202, 2007.

49 Greif JM, Pezzi CM, Klimberg VS, Bailey L and Zuraek M: Gender differences in breast cancer: analysis of 13,000 breast cancers in men from the National Cancer Data Base. Ann Surg Oncol 19(10): 3199-3204, 2012.

50 Iorfida M, Bagnardi V, Rotmensz N, Munzone E, Bonanni B, Viale G, Pruneri G, Mazza M, Cardillo A, Veronesi P, Luini A, Galimberti V, Goldhirsch A and Colleoni M: Outcome of male breast cancer: a matched single-institution series. Clin Breast Cancer 14(5): 371-377, 2014.

51 Gennari R, Curigliano G, Jereczek-Fossa BA, Zurrida S, Renne G, Intra M, Galimberti V, Luini A, Orecchia R, Viale G, Goldhrisch A and Veronesi U: Male breast cancer: a special therapeutic problem. Anything new? (Review). Int J Oncol 24(3): 663-670, 2004.
52 Haviland JS, Owen JR, Dewar JA, Agrawal RK, Barrett J, Barrett-Lee PJ and Dobbs HJ, Hopwood P, Lawton PA, Magee BJ, Mills J, Simmons S, Sydenham MA, Venables K, Bliss JM and Yarnold JR; START Trialists' Group: The UK Standardisation of Breast Radiotherapy (START) trials of radiotherapy hypofractionation for treatment of early breast cancer: 10-year follow-up results of two randomised controlled trials. Lancet Oncol 14(11): 1086-1094, 2013.

53 Whelan TJ, Pignol J-P, Levine MN, Julian JA, MacKenzie R, Parpia S, Shelley W, Grimard L, Bowen J, Lukka H, Perera F, Fyles A, Schneider K, Gulavita S and Freeman C: Long-Term results of hypofractionated radiation therapy for breast cancer. N Engl J Med 362(6): 513-520, 2010.

54 Haffty BG, Whelan T and Poortmans PM: Radiation of the internal mammary nodes: is there a benefit? J Clin Oncol 34(4): 297-299, 2016
Received September 29, 2017

Revised October 23, 2017

Accepted October 27, 2017 